Check for updates

Cite this: RSC Adv., 2019, 9, 38077

Received 16th September 2019 Accepted 3rd November 2019

DOI: $10.1039 / c 9 r a 07445 g$

rsc.li/rsc-advances

\section{Photoluminescence of $\mathrm{PdS}_{2}$ and $\mathrm{PdSe}_{2}$ quantum dotst}

\author{
Xinyu Wang, ${ }^{\text {ab }}$ Wayesh Qarony, (D) ab Ping Kwong Cheng, ${ }^{\text {ab }}$ Mohammad Ismail (D) ab \\ and Yuen Hong Tsang (D) *ab
}

Group-10 transition metal dichalcogenide (TMD) materials have recently attracted considerable attention in optoelectronics applications. However, so far their quantum dot (QD) counterparts with photoluminescence (PL) nature still remain to be revealed. In this study, 2 typical types of group-10 TMD material $\left(\mathrm{PdS}_{2}\right.$ and $\left.\mathrm{PdSe}_{2}\right)$ QDs are fabricated via liquid exfoliation using $\mathrm{N}$-methyl-2-pyrrolidone (NMP) solvent. The absorption and PL spectra of these QD solutions are studied, exhibiting excitation wavelength-dependent behaviors and large Stokes shifts. Furthermore, the quantum yield and decay lifetime are also investigated and analyzed. The obtained results suggest promising optoelectronic applications with group-10 TMD QDs in the future.

\section{Introduction}

The lack of an intrinsic band gap in graphene has stimulated research into alternative two-dimensional (2D) materials for semiconductor applications. ${ }^{1}$ Recently, traditional transitionmetal dichalcogenide (TMD) semiconductors have become very promising candidates among the $2 \mathrm{D}$ materials series owing to the direct band gap behavior in monolayer TMDs at the $K$ point, ${ }^{2}$ along with excellent electronic, catalytic, optical, and mechanical properties. ${ }^{3-12}$ Furthermore, TMD materials exhibit superior photoluminescence behavior, ${ }^{3,4}$ piezoelectric properties, ${ }^{13,14}$ and controllable optical performance by modulating valleys in the $k$ space. ${ }^{15-18}$ The development of several optoelectronic devices, such as strain sensors, ${ }^{19}$ transistors ${ }^{20}$ and highly sensitive and broadband photodetectors ${ }^{21-23}$ will highly benefit from the assistance of these inherent properties.

The research frontiers in TMDs are mainly focused on investigating novel semiconductor characteristics by combining various transition metal atoms with chalcogens ( $\mathrm{S}, \mathrm{Se}$, and $\mathrm{Te}){ }^{2}$ Several noble metal atoms, such as platinum $(\mathrm{Pt})$ and palladium (Pd) can bond to these four chalcogens, resulting in layer structure. In the material's atomic structure of such TMDs, each unit cell consists of a noble metal atom sandwiched by 2 chalcogen atoms, leading to the formation of a hexagonally plain structure. ${ }^{24-29}$ Unlike to the traditional TMDs materials these advanced TMDs materials again exhibit several unique material properties, such as superconductivity, high carrier mobility,

${ }^{a}$ The Hong Kong Polytechnic University Shenzhen Research Institute, Shenzhen, Guangdong, China. E-mail: yuen.tsang@polyu.edu.hk

${ }^{b}$ Department of Applied Physics and Materials Research Centre, The Hong Kong Polytechnic University, Hung Hom, Kowloon, Hong Kong, China

$\dagger$ Electronic supplementary information (ESI) available. See DOI: $10.1039 / \mathrm{c} 9 \mathrm{ra} 07445 \mathrm{~g}$ broad tunable band gap, and stability in the air. ${ }^{26,28-31}$ The application of such materials in optoelectronic devices is also wide with remarkable performances. For instance, $\mathrm{PtS}_{2}$ with (0.25 (bulk) to $1.6 \mathrm{eV}$ (monolayer)) indirect band gap ${ }^{28,29}$ has been applied in field-effect transistor (FET) ${ }^{29}$ Q-switched laser, ${ }^{25}$ and catalysis. ${ }^{32} \mathrm{PtSe}_{2}$, with a tunable indirect band gap from 0 (bulk) to $1.2 \mathrm{eV}$ (monolayer), has also been used in saturable absorber ${ }^{33}$ and broadband photodetectors. ${ }^{34,35}$ Then electronic, optical, and catalytic properties with bandgap tunability have also been studied in $\mathrm{PdS}_{2}$ under tensile strain, exhibiting semi-metallic characteristic even for the bilayer structure. ${ }^{36}$ Furthermore, the indirect bandgap with $1.0 \mathrm{eV}$ is found to appear in $\mathrm{PdS}_{2}$ when it reaches monolayer thickness, whereas the metallic characteristics are exhibited for its bulk counterpart. ${ }^{36} \mathrm{~A} \mathrm{PdS}_{2}$ logical junction has also recently been reported with $2.5 \mathrm{~nm}$ channel length and a gate voltage dependent $I-V$ characteristic. ${ }^{37}$ Additionally, indirect bandgap $\mathrm{PdSe}_{2}$ with a bandgap of $1.31 \mathrm{eV}$ has been exhibited for its monolayer structure and metallic for the bulk counterpart. ${ }^{26}$ The applications of $\mathrm{PdSe}_{2}$ based thermal electricity, ${ }^{38} \mathrm{FET}$, ${ }^{39}$ and photodetector $^{40}$ suggest its exceptional optoelectronics properties. In the beginning, the $\mathrm{PtS}_{2}$ was anticipated and experimentally demonstrated as that the photoluminescence (PL) signal is "too weak to be detected" owing to its indirect bandgap, even for the case of its monolayer structure. ${ }^{28}$ Nonetheless, the PL behavior of $\mathrm{PtS}_{2}$ has successfully observed via scaling down to quantum dots (QDs). ${ }^{41}$ However, the PL behaviors of $\mathrm{PdS}_{2}$ and $\mathrm{PdSe}_{2}$ are still remained obscure. Since $\mathrm{PdS}_{2}$ and $\mathrm{PdSe}_{2}$ exhibit similar crystal structure with $\mathrm{PtS}_{2}$, including the indirect bandgap, such group-10 TMDs materials arouse our interest for the investigation of PL performance.

QDs are defined when materials reach a size smaller than twice of their excitonic Bohr radius. QDs have been reported as 
a novel structure with exceptional large transition energy in comparison to their bulk or layer counterpart, resulting in enhanced PL performance of the materials; thanks to quantum confinement effect. ${ }^{\mathbf{4 2 - 4 4}}$ In a previous study, we successfully fabricated $\mathrm{PtS}_{2}$ QDs via low cost liquid exfoliation with water. ${ }^{41}$ Herein, 2 typical group-10 TMDs materials, $\mathrm{PdS}_{2}$ and $\mathrm{PdSe}_{2}$, QDs are fabricated with the aid of similar liquid exfoliation technique, while $\mathrm{N}$-methyl-2-pyrrolidone (NMP) is selected as solvent for its better compatibility of surface energy as compared to the water. $\mathrm{PtS}_{2}$ QDs solution is also fabricated with same method in order to assist analyzation by comparing with $\mathrm{PdS}_{2}$ and $\mathrm{PdSe}_{2}$ QDs. To our knowledge, this is the first experimental demonstration of optical characteristics of $\mathrm{PdS}_{2}$ and $\mathrm{PdSe}_{2}$ QDs, where the UV-Vis spectra, PL spectra and the decay lifetimes of $\mathrm{PtS}_{2}$ QDs, $\mathrm{PdS}_{2}$ QDs, and $\mathrm{PdSe}_{2}$ QDs are monitored and analyzed by comparing with each other.

\section{Experimental section}

\subsection{Materials fabrication}

In this study, $\mathrm{PdS}_{2}, \mathrm{PdSe}_{2}$, and $\mathrm{PtS}_{2}$ QDs were fabricated via liquid exfoliation from their bulk powder raw materials. NMP was selected to be the solvent for its compatible surface energy, resulting in stabilizing and preventing TMDs nanoparticles from agglomeration. In the first step of the fabrication process, a $50 \mathrm{mg}$ of $\mathrm{PtS}_{2}$ raw material (Alfa Aescar) was poured into $250 \mathrm{~mL}$ of NMP solution. Next, a probe sonication was applied to the mixture under $250 \mathrm{~W}$ power with $20 \mathrm{kHz}$ frequency for about 3 hours long, while $27{ }^{\circ} \mathrm{C}$ temperature was maintained throughout the process. In this case, the operation time of ultrasonic probe was set to $2 \mathrm{~s}$ at an interval of $4 \mathrm{~s}$. Then, $2 / 3$ of dispersion close to the liquid level was taken and stirred for $6 \mathrm{~h}$ under $140{ }^{\circ} \mathrm{C}$. The supernatant liquor was obtained by centrifugation at $2000 \mathrm{rpm}$ for $5 \mathrm{~min}$ to separate QDs from bulky raw materials. This QDs as-prepared solution was taken for the experiments and characterizations.

\subsection{Characterization}

The high-resolution images and lattice fringes of as-prepared QDs were observed via Transmission Electron Microscopy (TEM, Jeol JEM-2100F). The thickness of QDs was scanned under tapping mode with the aid of Atomic Force Microscopy (AFM, Bruker Nanoscope 8). Each of the AFM samples for QDS were prepared via drop casting the as-prepared QDs solution on the surface of quartz substrate followed by drying under $80^{\circ} \mathrm{C}$ in the air atmosphere. Element contained in as-prepared solution is confirmed by the Energy Dispersive X-ray Spectroscopy (EDX, ULTIM MAX 170) performed on Scanning Electron Microscopy (SEM, GeminiSEM 300). The samples for EDX and SEM measurements are fabricated by drop-casting on the silicon substrate following by drying under the air atmosphere. Chemical composition of raw materials was detected by X-ray photoelectron spectroscopy (XPS, ESCALAB 250Xi, Thermo Fisher Scientific) with achromatic $200 \mathrm{~W}$ Al K $\alpha$ as the X-ray source and the resolution of $0.10 \mathrm{eV}$. Before conducting the XPS measurement, the powders of raw materials were utilized to eliminate water in the oven under $60{ }^{\circ} \mathrm{C}$ for $3 \mathrm{~h}$. The $\mathrm{PL}$ measurement was performed with Edinburgh CD920. The emission spectra of QDs solution were monitored on excitation at given wavelength under ambient environment. The excitation source was Xenon lamp. Time-resolved measurements were monitored by HORIBA FluoroMax- 4 spectrometer for ultrafast studies and time-correlated single-photon counting (TCSPC) accessory for lifetime determinations. UV-Vis absorption spectroscopy was recorded by Shimadzu UV-2550.

\section{Results and discussion}

Fig. 1 is an illustration of TEM images for $\mathrm{PdS}_{2}$, and $\mathrm{PdSe}_{2}$ group-10 TMDs materials QDs. The TEM samples were prepared by drop-casting as-prepared QDs suspensions on holey copper grid, followed by a drying process in the ambient environment under $60^{\circ} \mathrm{C}$ for $1 \mathrm{~h}$. The morphologies and scattered distributions of $\mathrm{PdS}_{2}, \mathrm{PdSe}_{2}$, and $\mathrm{PtS}_{2}$ QDs can be clearly observed from Fig. 1e and $f$, and $S 1 c, \uparrow$ respectively. The statics of the corresponding size distributions are depicted in Fig. 1c and d, and $\mathrm{S} 1 \mathrm{~b} \dagger$ for number of $104 \mathrm{PdS}_{2}, 106 \mathrm{PdSe}_{2} \mathrm{QDs}$, and $143 \mathrm{PtS}_{2}$, respectively, pronouncing a statistical estimation of their average diameters of 4.99, 4.17, and $4.73 \mathrm{~nm}$. High resolution images of $\mathrm{PdS}_{2}, \mathrm{PdSe}_{2}$, and $\mathrm{PtS}_{2}$ QDs were captured in Fig. 1c and $\mathrm{d}$, and $\mathrm{S} 1 \mathrm{~b}, \dagger$ respectively, indicating the high crystallinity of the as-prepared samples. For the $\mathrm{PdS}_{2}$ QDs with a determined lattice distance of $0.27 \mathrm{~nm}$ is corresponding to the (200) plane, which agrees well with a simulated data as recently reported in the literature. ${ }^{36}$ Then the $\mathrm{PdSe}_{2}$ QDs shows a $0.27 \mathrm{~nm}$ lattice periodicity that matches its (200) crystalline plane. ${ }^{24}$ The interplanar spacing of $0.29 \mathrm{~nm}$ for $\mathrm{PtS}_{2}$ QDs as observed in Fig. S1b $\dagger$ is corresponding to (100) plane..$^{28,29,41}$ The results imply that the ultrasonic energy is sufficient to separate layered group-10 TMDs materials from the van der Waals forces and even splits them into nanoscales. Thanks to the outstanding stability of group-10 TMDs materials, which allows to obtain good crystallinity in the materials.

Further investigation on QDs' height profiles and height distributions were conducted via AFM measurement as shown in Fig. 2. The QDs were scattered on the quartz substrates by scanning processes. The scan size was set to be $1 \times 1 \mu \mathrm{m}^{2}$ and the observation of QDs was taken place randomly on the substrates. The height variation of $\mathrm{PdS}_{2}, \mathrm{PdSe}_{2}$, and $\mathrm{PtS}_{2}$ QDS can be clearly distinguished along line profiles as depicted in Fig. 2a and b, S2a, $\uparrow$ respectively. The statics of $54 \mathrm{PdS}_{2}$ QDs are shown in Fig. 2c, indicating an average height of $2.61 \mathrm{~nm}$, which can be considered as 6 to 7 layers. ${ }^{27}$ The height information of 25 observed $\mathrm{PdSe}_{2}$ QDs is recorded in Fig. 2d. The thickness of such QDs are assumed to be 4 to 5 layers referring to $1.99 \mathrm{~nm}$ average height. ${ }^{27}$ The average height of $38 \mathrm{PtS}_{2}$ QDs is determined to be $2.82 \mathrm{~nm}$, suggesting 5 to 6 layers' thickness, ${ }^{28}$ and their height distribution is depicted in Fig. S2b. $\dagger$

The element compositions of as-prepared QDs solutions are detected via the Scanning Electron Microscopy (SEM) and the Energy Dispersive X-ray Spectroscopy (EDX) mapping. The mapping analysis shown in Fig. 3a-c confirms the existence of Pd and $\mathrm{S}$ elements in $\mathrm{PdS}_{2}$ QDs solution. The consistent 

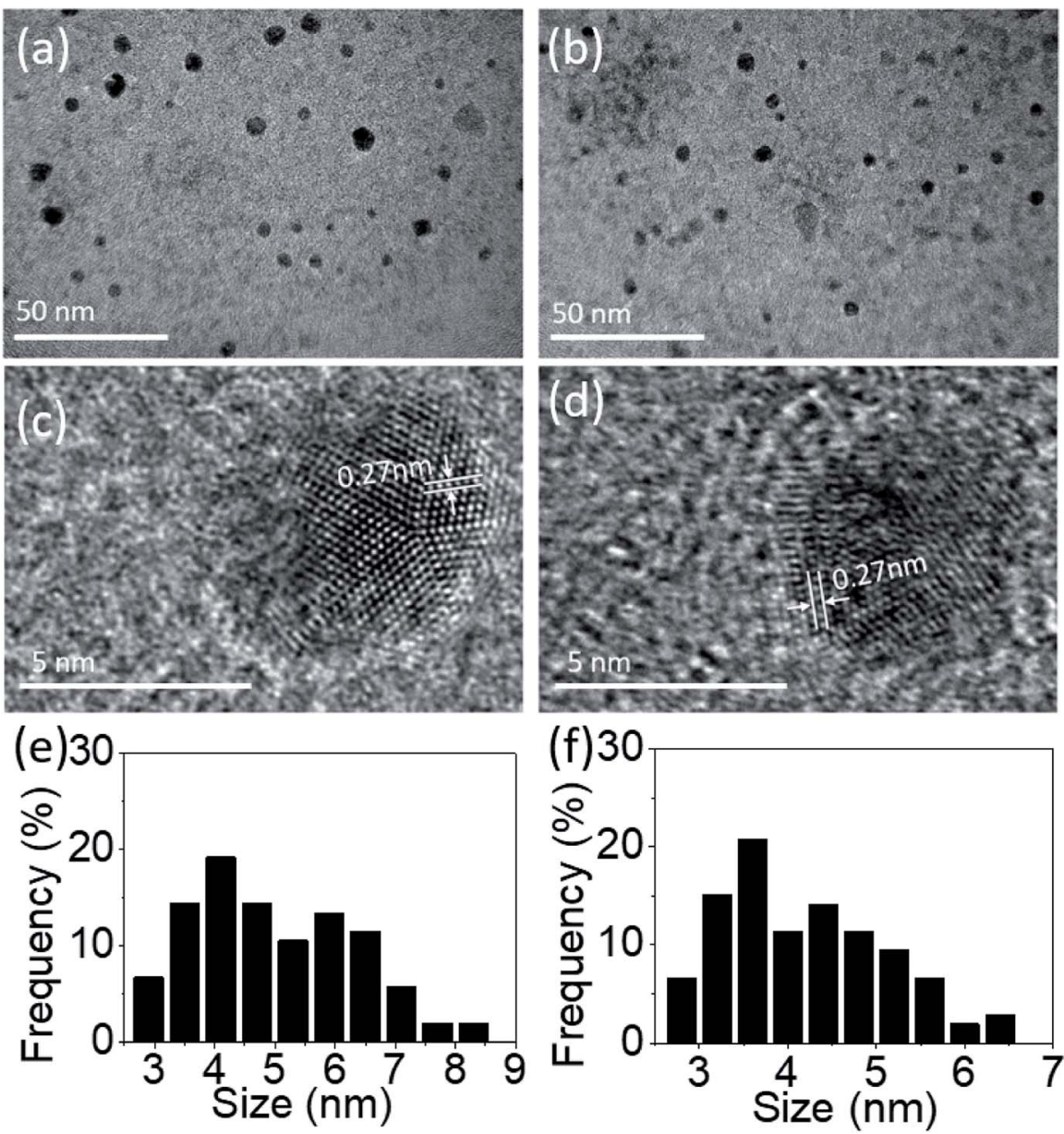

Fig. 1 TEM images of (a) PdS 2 QDs solution and (b) $P d S_{2}$ QDs solution; high resolution TEM images of a typical (c) PdS 2 QD and (d) PdSe $e_{2} Q D$; and size distributions based on multiple images of (e) $\mathrm{PdS}_{2}$ QDs and (f) $\mathrm{PdSe}_{2}$ QDs.

distributions of Pd and Se shown in Fig. 3d-f verify the elements in $\mathrm{PdSe}_{2}$ QDs solution. The element mapping images in Fig. S3† evident the elements contained in $\mathrm{PtS}_{2}$ QDs solution since both $\mathrm{Pt}$ and $\mathrm{S}$ are accordantly distributed along the film surface.

The EDX is not suitable used as quantitative analysis method. Therefore, the XPS measurement was conducted on the raw powder materials counterparts in order to investigate their chemical compositions as shown in Fig. 4. For Pt4f spectra of $\mathrm{PtS}_{2}$, deconvolution of the line shape reveals two doublets, $\mathrm{Pt}^{2+}$ and $\mathrm{Pt}^{4+}$, essential to reconstruct $\mathrm{Pt}$ signals, as shown in Fig. S4a. $\dagger \mathrm{Pt}^{2+}$ with level positions of $\mathrm{Pt}_{4 \mathrm{f}_{7 / 2}}$ and $\mathrm{Pt} 4 \mathrm{f}_{5 / 2}$ are fitted at $71.98 \mathrm{eV}$ and $75.38 \mathrm{eV}$, along with $\mathrm{Pt}^{4+} 4 \mathrm{f}_{7 / 2}$ and $\mathrm{Pt}^{4+} 4 \mathrm{f}_{5 / 2}$ fitted at $71.98 \mathrm{eV}$ and $75.38 \mathrm{eV}$, respectively. S2p deconvolution as shown in Fig. S4b $\uparrow$ can be conducted showing one doublets: $\mathrm{S} 2 \mathrm{p}_{3 / 2}$ at $162.78 \mathrm{eV}$ and $\mathrm{S} 2 \mathrm{p}_{1 / 2}$ at $164.18 \mathrm{eV}$. The signal with $168.08 \mathrm{eV}$ binding energy refers to sulphate series constituting $\mathrm{HSO}_{4}{ }^{-}$or $\mathrm{SO}_{4}{ }^{2-} \cdot{ }^{32,45}$ Such considerable intensity of sulphate signal indicates partial oxidation on the surface of the $\mathrm{PtS}_{2}$ raw materials, resulting in $\mathrm{Pt}^{2+}$ as predominant doublet. The atomic percentage of $\mathrm{Pt}$ and $\mathrm{S}$ is determined to be $17.79 \%$ and $27.97 \%$. The stoichiometric ratio is obtained as less than 0.5 , which may be due to the origination of sulphate series from surface oxidation during drying process. For $\mathrm{PdS}_{2}$, signals of $\mathrm{Pd} 3 \mathrm{~d}_{5 / 2}$ and $P d 3 d_{3 / 2}$ are shown in Fig. $4 \mathrm{a}$ with binding energies of $336.08 \mathrm{eV}$ and $341.38 \mathrm{eV}$. The S2p spectra for $\mathrm{PdS}_{2}$ can be divided into two chemical states ${ }^{46}$ as shown in Fig. $4 \mathrm{~b}$. For the case of $\mathrm{PtS}_{2}$ raw materials, $\mathrm{S}(\mathrm{I}) 2 \mathrm{p}_{3 / 2}$ and $\mathrm{S}(\mathrm{I}) 2 \mathrm{p}_{1 / 2}$ are simulated at $161.08 \mathrm{eV}$ and $163.38 \mathrm{eV}$, while $\mathrm{S}(\mathrm{II}) 2 \mathrm{p}_{3 / 2}$ and $\mathrm{S}(\mathrm{II}) 2 \mathrm{p}_{1 / 2}$ with $162.28 \mathrm{eV}$ and $164.38 \mathrm{eV}$ exhibit similar to the S2p spectra. $\mathrm{PdS}_{2}$ stored under ambient conditions with no detectable sulphate series signal implies its high stability. The atomic percentage of Pd and S are found to be $3.08 \%$ and $6.96 \%$ on the surface, exhibiting a stoichiometric ratio very close to $1 / 2$ due to probably the absence of oxidation. The level positions of $\mathrm{Pd}_{3} \mathrm{~d}_{5 / 2}$ and $\mathrm{Pd}_{3} \mathrm{~d}_{3 / 2}$ in $\mathrm{PdSe}_{2}$ with $336.18 \mathrm{eV}$ and $341.48 \mathrm{eV}$ as depicted in Fig. $4 \mathrm{c}$ agree well with the presence of Pd signals in $\mathrm{PdS}_{2}$. The deconvolution of Se element gives rising to $\mathrm{Se} 3 \mathrm{~d}_{5 / 2}$ signal at $54.18 \mathrm{eV}$ and $\mathrm{Se}_{\mathrm{d}} \mathrm{d}_{3 / 2}$ signal at $54.98 \mathrm{eV}$ as shown in Fig. $4 \mathrm{~d}$. The atomic percentage of $6.76 \%$ and $15.11 \%$ for the Pd and Se elements support the idea of air stability as recently reported in the literature. ${ }^{26}$

The PL emission spectra of $\mathrm{PdS}_{2}$, and $\mathrm{PdSe}_{2}$ QDs show excitation wavelength-dependent behaviors, i.e. the wavelength of PL emission peak red-shifts under crescent excitation 

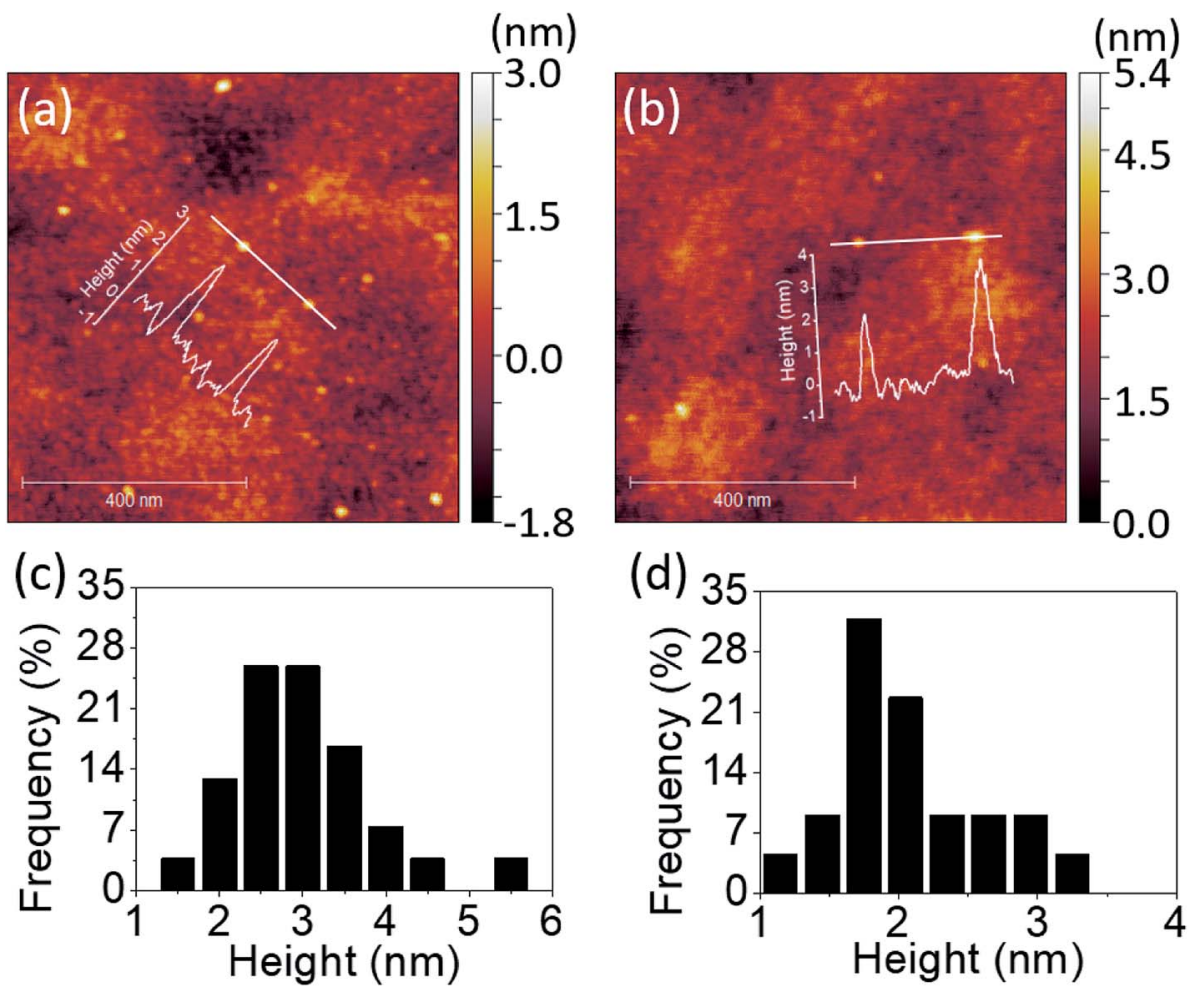

Fig. 2 Line profiles and corresponding AFM images of (a) $\mathrm{PdS}_{2} \mathrm{QDs}$, and (b) $\mathrm{PdSe}_{2} \mathrm{QDs}$; height distributions based on several images of (c) PdS QDs, and (d) $\mathrm{PdSe}_{2}$ QDs.

wavelength, which have been widely reported by several studies on semiconductor QDs, ${ }^{47,48}$ traditional TMDs QDs, ${ }^{42,44}$ and carbon QDs. ${ }^{49,50}$ Due to quantum size effect, the poly-diversity of QDs sizes give rising to the variation of band gap energies. The larger QDs exhibit lower band gap energies, and vice versa. The PL spectra of $\mathrm{PdS}_{2}$ QDs as shown in Fig. 5a were observed from $400 \mathrm{~nm}$ to $567 \mathrm{~nm}$ under the excitation ranging from $320 \mathrm{~nm}$ to $480 \mathrm{~nm}$. The highest PL peak is determined to be $491 \mathrm{~nm}$ for the
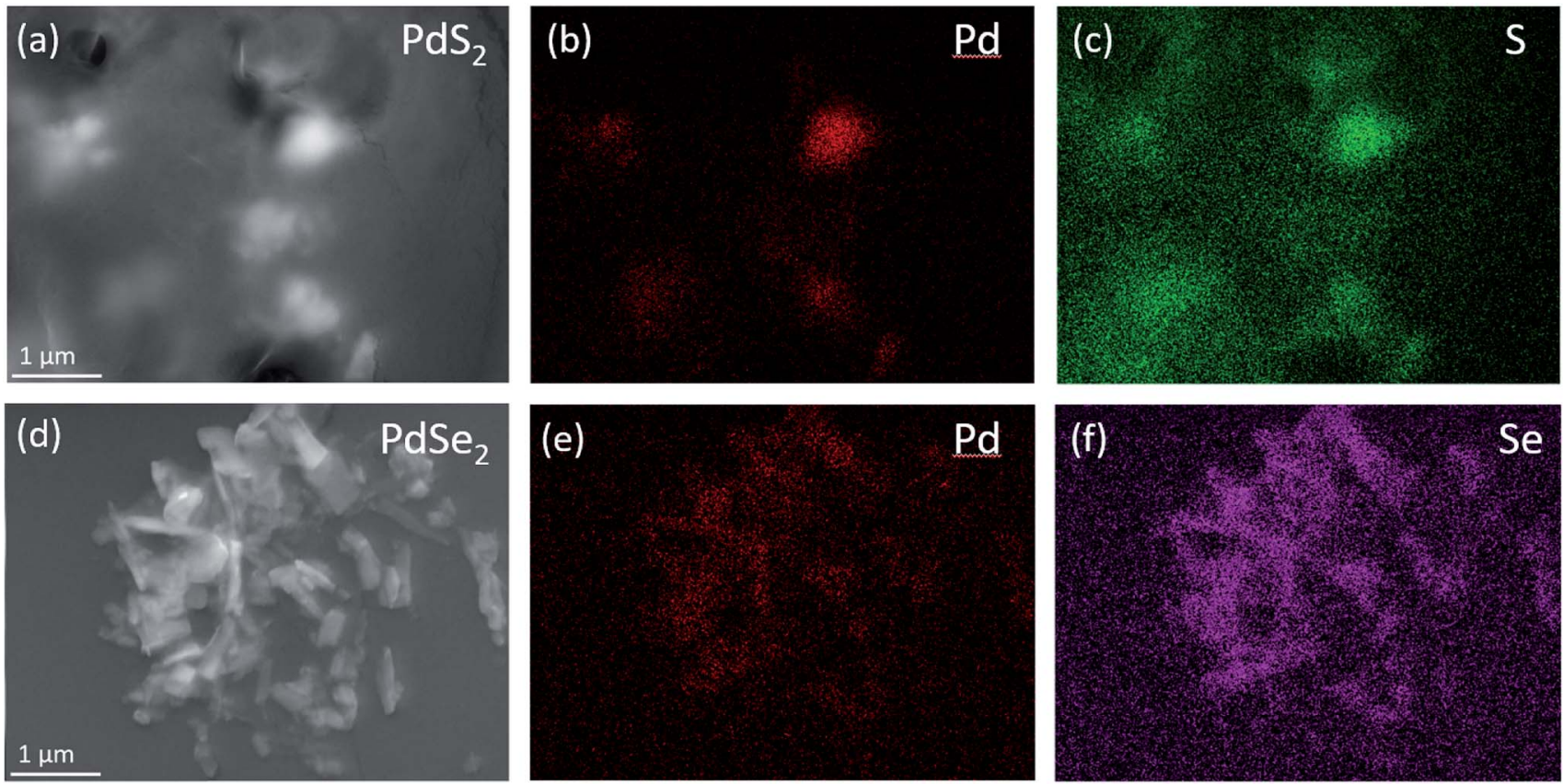

Fig. 3 (a) SEM image of $\mathrm{PdS}_{2}$ QDs solution drop-casting on silicon substrate; (b and c) EDX elemental maps of Pd and S elements in (a); (d) SEM image of $\mathrm{PdSe}_{2}$ QDs solution drop-casting on silicon substrate; (e and f) EDX elemental maps of Pd and Se elements in (d). 

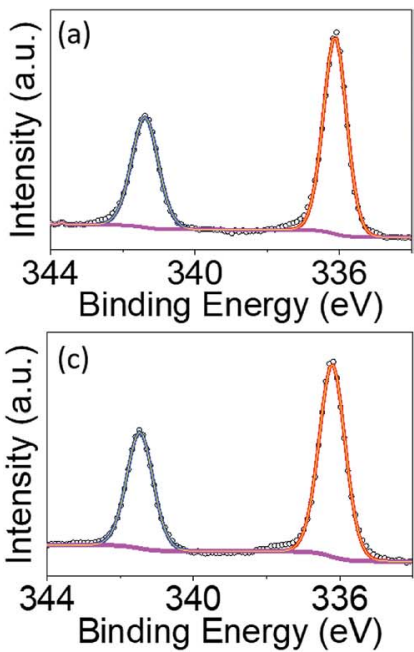
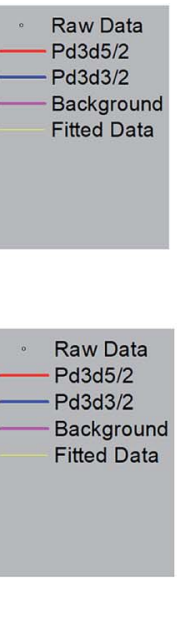
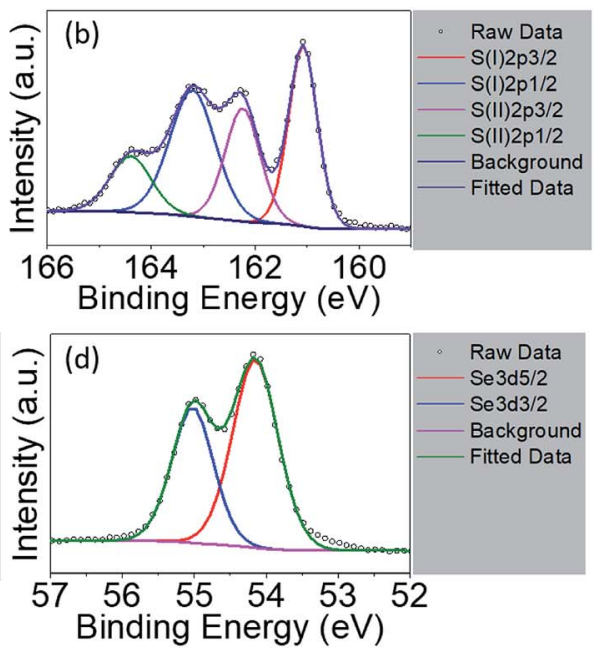

Fig. 4 High resolution X-ray photoelectron spectra of $\mathrm{PdS}_{2}$ for (a) Pd3d region and (b) S2p region; PdSe $\mathrm{f}_{2}$ for (c) Pd3d region and (d) Se3d region.

excitation wavelength of $400 \mathrm{~nm}$. The PL spectra of $\mathrm{PdSe}_{2}$ are depicted in Fig. 5b, displaying emission peaks ranging $379 \mathrm{~nm}$ to $551 \mathrm{~nm}$, while the excitation wavelength was being tuned from $300 \mathrm{~nm}$ to $480 \mathrm{~nm}$. The $340 \mathrm{~nm}$ excitation wavelength presents a maximum emission peak at $413 \mathrm{~nm}$. The $\mathrm{PtS}_{2}$ QDs sample exhibits PL peak wavelength ranging from 381.5 to $548 \mathrm{~nm}$ while excitation wavelength shifts from $300 \mathrm{~nm}$ to $480 \mathrm{~nm}$ as shown in Fig. S5. $\uparrow$ The maximum emission peak could be found at $468.5 \mathrm{~nm}$ for the excitation wavelength of $380 \mathrm{~nm}$. The maximum emission peak wavelengths demonstrate a trend of $\mathrm{PdSe}_{2}$ QDs $<\mathrm{PdS}_{2}$ QDs, which might be owing to including but not limited to their intrinsic chemical property. The intrinsic bandgaps may also play important role in defining the emission peak wavelength. Since monolayer $\mathrm{PdS}_{2}$ holds a smaller bandgap than monolayer $\mathrm{PdSe}_{2}$, the $\mathrm{PdS}_{2}$ sample exhibits a substantial redshift $v s$. $\mathrm{PdSe}_{2}$ sample. This PL emission peak trend also accords with their average sizes determined via TEM characterizations, which may further prove the quantum size effect.

The absorption spectra are depicted in Fig. 6 with black lines. The distinct absorption peaks at 330, 274, and $307 \mathrm{~nm}$ can be observed in Fig. 6a and 5b, and $\mathrm{S} 5 \dagger$ for the solutions of $\mathrm{PdS}_{2}$, and $\mathrm{PdSe}_{2}$, and $\mathrm{PtS}_{2}$ QDs, respectively. The maximum emission peaks (in blue lines) for all QDs samples and their corresponding photoluminescence excitation (PLE) spectra (in red line) are also displayed in Fig. 6. The maximum PLE peaks for $\mathrm{PdS}_{2}$, and $\mathrm{PdSe}_{2}$, and $\mathrm{PtS}_{2}$ QDs samples exhibit at 397.5, 346, and $377 \mathrm{~nm}$ as shown in Fig. 6a and b, and S6, $\uparrow$ respectively. These PLE peaks agree well with the previous PL emission analysis, implying to $0.59 \mathrm{eV}, 0.58 \mathrm{eV}$, and $0.64 \mathrm{eV}$ stokes shifts for the $\mathrm{PdS}_{2}, \mathrm{PdSe}_{2}$, and $\mathrm{PtS}_{2}$, respectively. Such large stokes shifts are caused by the quantum confinement effect when materials size approaches to the atomic scale, resulting in dramatic expansion of spatial overlaps for electron-hole wave functions. ${ }^{51}$ The splitting of the lowest singlet fine structure states and highest triplet states grows much larger comparing to their layers or bulky structure. ${ }^{51,52}$ The dark exciton ensues when excitation experiences a rapid thermalization process from active singlet state to passive triplet state, leading to red shift of PL emission spectrum and larger stokes shift. Quantum yield (QY) of $\mathrm{PdS}_{2}, \mathrm{PdSe}_{2}$, and $\mathrm{PtS}_{2}$ QDs are evaluated to be $11.11 \%$, $7.18 \%$, and $14.42 \%$, respectively and tabulated in Table 1 . The PL QY for as-prepared QDs samples are calculated by eqn (1).

$$
\mathrm{QY}=\frac{\eta^{2}}{\eta_{\mathrm{ref}}^{2}} \frac{A_{\mathrm{ref}}}{A} \frac{F}{F_{\text {ref }}} \mathrm{QY}_{\text {ref }}
$$
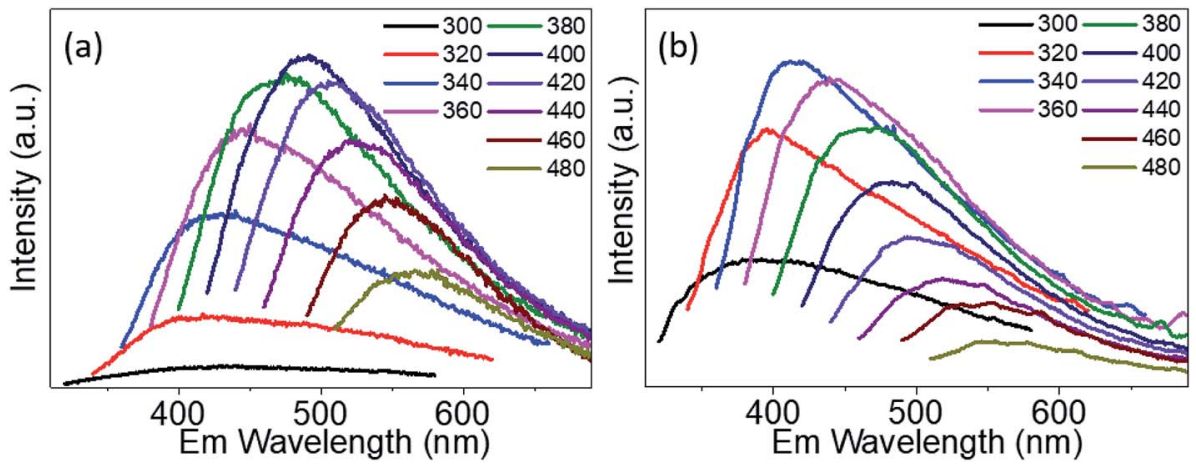

Fig. 5 Emission (Em) spectra of (a) $\mathrm{PdS}_{2}$ QDs solution, and (b) $\mathrm{PdSe}_{2}$ QDs solution. 
(a)

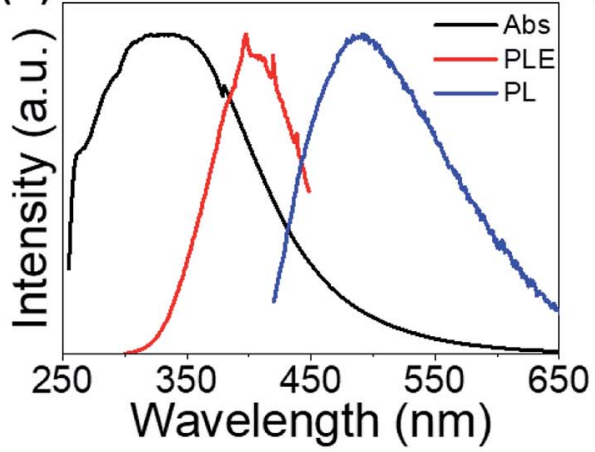

(b)

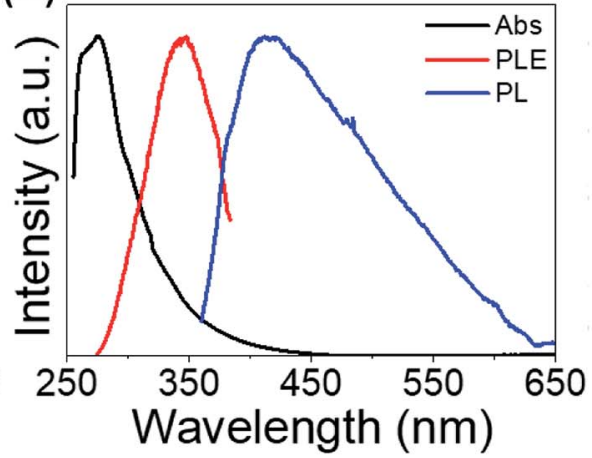

Fig. 6 Normalized absorption spectra (black curve) for (a) PdS 2 QDs and (b) PdSe 2 QDs solutions. Photoluminescence excitation (PLE) spectra (red curve) for (a) 491 and (b) 413 nm emission wavelengths, which are observed at the peaks of the corresponding emission spectra (blue curve).

Table 1 Quantum yields of $\mathrm{PtS} \mathrm{S}_{2} \mathrm{QDs}, \mathrm{PdS}_{2} \mathrm{QDs}$, and $\mathrm{PdS} \mathrm{e}_{2}$ QDs solutions

\begin{tabular}{lllll}
\hline & $A$ & $F$ & $\eta$ & QY \\
\hline Quinine sulfate & 0.024 & 6095040 & 1.33 & $54 \%$ \\
PtS $_{2}$ QDs & 0.036 & 1459610 & 1.47 & $14.42 \%$ \\
PdS $_{2}$ QDs & 0.027 & 850509 & 1.47 & $11.11 \%$ \\
PdSe $_{2}$ QDs & 0.034 & 619276 & 1.47 & $7.18 \%$ \\
\hline
\end{tabular}

where, $\eta$ represents the refractive index of the solvent. The quinine sulfate is dissolved in $\mathrm{H}_{2} \mathrm{SO}_{4}$ to prepare reference solution by controlling its absorbance similar to the as-prepared $\mathrm{PdS}_{2}, \mathrm{PdSe}_{2}$, and $\mathrm{PtS}_{2}$ solutions. Quinine sulfate solution holds refractive index of 1.33, while the QDs is dissolved in NMP solution which holds a refractive index of 1.47. $F$ and $A$ are referring to the integrated emission intensity and absorbance, respectively for samples and reference compound.

In the next step, the time-resolved PL decay measurement is performed at room temperature as depicted in Fig. 7, while $\mathrm{PdS}_{2}, \mathrm{PdSe}_{2}$, and $\mathrm{PtS}_{2}$ QDs samples are excited by $377,397.5$, and $346 \mathrm{~nm}$ wavelengths, respectively. The decay lifetime curves of QDs samples are monitored and fitted by dual-exponential

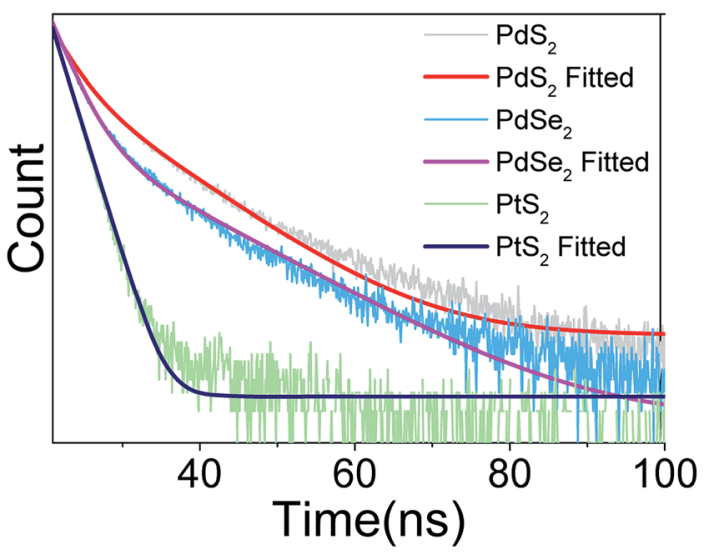

Fig. 7 Decay profile of $\mathrm{PdS}_{2} \mathrm{QDs}$, $\mathrm{PdS} \mathrm{e}_{2} \mathrm{QDs}$, and $\mathrm{PtS}_{2}$ QDs solutions.
Table 2 Fitted decay lifetimes for $\mathrm{PtS}_{2} \mathrm{QDs}, \mathrm{PdS}_{2} \mathrm{QDs}$, and $\mathrm{PdS} \mathrm{S}_{2} \mathrm{QDs}$ solutions

\begin{tabular}{llllrl}
\hline & $a_{1}$ & $\tau_{1} / \mathrm{ns}$ & \multicolumn{1}{l}{$a_{2}$} & $\tau_{2} / \mathrm{ns}$ & $\tau_{\text {ave }} / \mathrm{ns}$ \\
\hline $\mathrm{PtS}_{2}$ QDs & $8.85 \times 10^{8}$ & 0.15 & $9.32 \times 10^{8}$ & 1.81 & 1.69 \\
$\mathrm{PdS}_{2}$ QDs & 25672 & 9.06 & $1.77 \times 10^{7}$ & 2.63 & 2.67 \\
$\mathrm{PdSe}_{2}$ QDs & $6.33 \times 10^{7}$ & 3.64 & 6024 & 10.93 & 2.37 \\
\hline
\end{tabular}

function. The function presented in eqn (2) explains that the decay curve is dominated by two de-excitation processes in the surface states and the core states, corresponding to a long-lived component $\tau_{1}$ and a short-lived component $\tau_{2} \cdot{ }^{53,54}$ The average lifetime $\left(\tau_{\text {ave }}\right)$ is estimated by substituting parameters of eqn (2) into eqn (3). The fitted values as listed in Table 2 suggest that $\tau_{1}$ dominates the decay lifetime for all QDs samples, indicating that their core states play essential role in the PL decay kinetics. The Pd based QDs may exhibit prolonged decay lifetimes than the Pt based group-10 TMDs QDs according to $\tau_{\text {ave }}$. The better stabilities of $\mathrm{PdS}_{2}$ and $\mathrm{PdSe}_{2}$ may attribute to this longer decay lifetime.

$$
\begin{gathered}
A(t)=a_{1} \exp \left(-\tau / \tau_{1}\right)+a_{2} \exp \left(-\tau / \tau_{2}\right) \\
\tau_{\text {ave }}=\frac{a_{1} \tau_{1}^{2}+a_{2} \tau_{2}^{2}}{a_{1} \tau_{1}+a_{2} \tau_{2}}
\end{gathered}
$$

\section{Conclusions}

In this study, 2 typical group-10 TMDs materials QDs were fabricated via solvent exfoliation and investigated by comparing with a different group-10 TMDs $\mathrm{PtS}_{2}$ QDs. The as-prepared $\mathrm{PdS}_{2}$ and $\mathrm{PdSe}_{2}$ QDs exhibit average diameters of 4.99 and $4.17 \mathrm{~nm}$, while their average thicknesses were determined as 2.61 and $1.99 \mathrm{~nm}$. Very good air stabilities were observed for $\mathrm{PdS}_{2}$ and $\mathrm{PdSe}_{2}$. The optical characteristics for those QDs solutions were monitored, exhibiting excitation wavelength-dependent 
behavior and large stokes shifts. The PL emission wavelengths might be strongly related to the size of QDs due to quantum size effect. This study is basically a short demonstration of simple synthesis process using solvent exfoliation and several optical performance parameters for two different group-10 TMDs materials of $\mathrm{PdS}_{2}$ and $\mathrm{PdSe}_{2}$ QDs. Most importantly, to our knowledge, so far this is the first demonstration of PL behaviors for $\mathrm{PdS}_{2}$ and $\mathrm{PdSe}_{2}$ QDs. We believe that this study with some excellent optical properties of these noble 2D materials should be beneficial for applications related to real time imaging, single molecule detection, light-emitting diode, and biosensing in addressing some analytical and biological issues which are currently being encountered in the fields.

\section{Conflicts of interest}

There are no conflicts to declare.

\section{Acknowledgements}

This work is financially supported by the Science and Technology Innovation Commission of Shenzhen (JCYJ20180306173805740 and JCYJ20170303160136888).

\section{Notes and references}

1 A. Gupta, T. Sakthivel and S. Seal, Prog. Mater. Sci., 2015, 73, 44-126.

2 C.-H. Chang, X. Fan, S.-H. Lin and J.-L. Kuo, Phys. Rev. B: Condens. Matter Mater. Phys., 2013, 88, 195420.

3 X. Fu, F. Li, J.-F. Lin, Y. Gong, X. Huang, Y. Huang, B. Han, Q. Zhou and T. Cui, J. Phys. Chem. Lett., 2017, 8, 35563563; L. Li and Y. Zhang, Nano Res., 2017, 10, 2527-2534.

4 A. Surrente, D. Dumcenco, Z. Yang, A. Kuc, Y. Jing, T. Heine, Y.-C. Kung, D. K. Maude, A. Kis and P. Plochocka, Nano Lett., 2017, 17, 4130-4136.

5 L. Li and Y. Zhang, Nano Res., 2017, 10, 2527-2534.

6 S. Deng, L. Li and M. Li, Phys. E, 2018, 101, 44-49.

7 A. Castellanos-Gomez, R. van Leeuwen, M. Buscema, H. S. J. van der Zant, G. A. Steele and W. J. Venstra, $A d v$. Mater., 2013, 25, 6719-6723.

8 K.-D. Park, O. Khatib, V. Kravtsov, G. Clark, X. Xu and M. B. Raschke, Nano Lett., 2016, 16, 2621-2627.

9 R. Addou, S. McDonnell, D. Barrera, Z. Guo, A. Azcatl, J. Wang, H. Zhu, C. L. Hinkle, M. Quevedo-Lopez, H. N. Alshareef, L. Colombo, J. W. P. Hsu and R. M. Wallace, ACS Nano, 2015, 9, 9124-9133.

10 C. Chen, W. Mei, W. Yu, X. Chen, L. Zeng, Y. Tsang, Z. Chao and X. Liu, RSC Adv., 2018, 8, 17399-17409.

11 S. Ma, L. Zeng, L. Tao, C. Y. Tang, H. Yuan, H. Long, P. K. Cheng, Y. Chai, C. Chen, K. H. Fung, X. Zhang, S. P. Lau and Y. H. Tsang, Sci. Rep., 2017, 7, 3125.

12 G. Liang, L. Tao, Y. H. Tsang, L. Zeng, X. Liu, J. Li, J. Qu and Q. Wen, J. Mater. Chem. C, 2019, 7, 495-502.

13 W. Wu, L. Wang, Y. Li, F. Zhang, L. Lin, S. Niu, D. Chenet, X. Zhang, Y. Hao, T. F. Heinz, J. Hone and Z. L. Wang, Nature, 2014, 514, 470.
14 H. Zhu, Y. Wang, J. Xiao, M. Liu, S. Xiong, Z. J. Wong, Z. Ye, Y. Ye, X. Yin and X. Zhang, Nat. Nanotechnol., 2014, 10, 151. 15 S. Wu, J. S. Ross, G.-B. Liu, G. Aivazian, A. Jones, Z. Fei, W. Zhu, D. Xiao, W. Yao, D. Cobden and X. Xu, Nat. Phys., 2013, 9, 149.

16 G. Sallen, L. Bouet, X. Marie, G. Wang, C. R. Zhu, W. P. Han, Y. Lu, P. H. Tan, T. Amand, B. L. Liu and B. Urbaszek, Phys. Rev. B: Condens. Matter Mater. Phys., 2012, 86, 81301.

17 H. Zeng, J. Dai, W. Yao, D. Xiao and X. Cui, Nat. Nanotechnol., 2012, 7, 490.

18 T. Cao, G. Wang, W. Han, H. Ye, C. Zhu, J. Shi, Q. Niu, P. Tan, E. Wang, B. Liu and J. Feng, Nat. Commun., 2012, 3, 887.

19 F. Yu, Q. Liu, X. Gan, M. Hu, T. Zhang, C. Li, F. Kang, M. Terrones and R. Lv, Adv. Mater., 2017, 29, 1603266.

20 K. F. Mak, K. L. McGill, J. Park and P. L. McEuen, Science, 2014, 344, 1489-1492.

21 D. Wu, Z. Lou, Y. Wang, Z. Yao, T. Xu, Z. Shi, J. Xu, Y. Tian, X. Li and Y. H. Tsang, Sol. Energy Mater. Sol. Cells, 2018, 182, 272-280.

22 Z. Lou, L. Zeng, Y. Wang, D. Wu, T. Xu, Z. Shi, Y. Tian, X. Li and Y. H. Tsang, Opt. Lett., 2017, 42, 3335-3338.

23 L. Zeng, L. Tao, C. Tang, B. Zhou, H. Long, Y. Chai, S. P. Lau and Y. H. Tsang, Sci. Rep., 2016, 6, 20343.

24 J. Lin, S. Zuluaga, P. Yu, Z. Liu, S. T. Pantelides and K. Suenaga, Phys. Rev. Lett., 2017, 119, 16101.

25 X. Wang, P. K. Cheng, C. Y. Tang, H. Long, H. Yuan, L. Zeng, S. Ma, W. Qarony and Y. H. Tsang, Opt. Express, 2018, 26, 13055-13060.

26 A. D. Oyedele, S. Yang, L. Liang, A. A. Puretzky, K. Wang, J. Zhang, P. Yu, P. R. Pudasaini, A. W. Ghosh, Z. Liu, C. M. Rouleau, B. G. Sumpter, M. F. Chisholm, W. Zhou, P. D. Rack, D. B. Geohegan and K. Xiao, J. Am. Chem. Soc., 2017, 139, 14090-14097.

27 A. Hamidani, B. Bennecer and K. Zanat, J. Phys. Chem. Solids, 2010, 71, 42-46.

28 Y. Zhao, J. Qiao, P. Yu, Z. Hu, Z. Lin, S. P. Lau, Z. Liu, W. Ji and Y. Chai, Adv. Mater., 2016, 28, 2399-2407.

29 L. Li, W. Wang, Y. Chai, H. Li, M. Tian and T. Zhai, Adv. Funct. Mater., 2017, 27, 1701011.

30 Y. Zhao, J. Qiao, Z. Yu, P. Yu, K. Xu, S. P. Lau, W. Zhou, Z. Liu, X. Wang, W. Ji, et al., Adv. Mater., 2016, 29, 0935-9648.

31 M. A. ElGhazali, P. G. Naumov, H. Mirhosseini, V. Sü\ss, L. Müchler, W. Schnelle, C. Felser and S. A. Medvedev, Phys. Rev. B, 2017, 96, 60509.

32 X. Chia, A. Adriano, P. Lazar, Z. Sofer, J. Luxa and M. Pumera, Adv. Funct. Mater., 2016, 26, 4306-4318.

33 L. Tao, X. Huang, J. He, Y. Lou, L. Zeng, Y. Li, H. Long, J. Li, L. Zhang and Y. H. Tsang, Photonics Res., 2018, 6, 750-755.

34 L. Zeng, S. Lin, Z. Li, Z. Zhang, T. Zhang, C. Xie, C. Mak, Y. Chai, S. P. Lau, L. Luo and Y. H. Tsang, Adv. Funct. Mater., 2018, 28, 1705970.

35 L. Zeng, S. Lin, Z. Lou, H. Yuan, H. Long, Y. Li, W. Lu, S. P. Lau, D. Wu and Y. H. Tsang, NPG Asia Mater., 2018, 10, 352-362.

36 S. Deng, L. Li and Y. Zhang, ACS Appl. Nano Mater., 2018, 1, 1932-1939. 
37 M. Ghorbani-Asl, A. Kuc, P. Miró and T. Heine, Adv. Mater., 2016, 28, 853-856.

38 M. Sun, J.-P. Chou, L. Shi, J. Gao, A. Hu, W. Tang and G. Zhang, ACS Omega, 2018, 3, 5971-5979.

39 W. L. Chow, P. Yu, F. Liu, J. Hong, X. Wang, Q. Zeng, C.-H. Hsu, C. Zhu, J. Zhou, X. Wang, J. Xia, J. Yan, Y. Chen, D. Wu, T. Yu, Z. Shen, H. Lin, C. Jin, B. K. Tay and Z. Liu, Adv. Mater., 2017, 29, 1602969.

40 L.-H. Zeng, D. Wu, S.-H. Lin, C. Xie, H.-Y. Yuan, W. Lu, S. P. Lau, Y. Chai, L.-B. Luo, Z.-J. Li and Y. H. Tsang, Adv. Funct. Mater., 2019, 29, 1970005.

41 X. Wang, H. Long, Y. Hong, C. Y. Tang and H. Yuan, J. Lumin., 2019, 211, 227-232.

42 Z. X. Gan, L. Z. Liu, H. Y. Wu, Y. L. Hao, Y. Shan, X. L. Wu and P. K. Chu, Appl. Phys. Lett., 2015, 106, 233113.

43 L. Lin, Y. Xu, S. Zhang, I. M. Ross, A. C. M. Ong and D. A. Allwood, ACS Nano, 2013, 7, 8214-8223.

44 S. Xu, D. Li and P. Wu, Adv. Funct. Mater., 2015, 25, 11271136.

45 A. A. Audi and P. M. A. Sherwood, Surf. Interface Anal., 2000, 29, 265-275.
46 G. Dodero, L. De Michieli, O. Cavalleri, R. Rolandi, L. Oliveri, A. Daccà and R. Parodi, Colloids Surf., A, 2000, 175, 121-128. 47 X. L. Wu, J. Y. Fan, T. Qiu, X. Yang, G. G. Siu and P. K. Chu, Phys. Rev. Lett., 2005, 94, 26102.

48 A. M. Smith and S. Nie, Analyst, 2004, 129, 672-677.

49 M. Hassan, E. Haque, K. R. Reddy, A. I. Minett, J. Chen and V. G. Gomes, Nanoscale, 2014, 6, 11988-11994.

50 X. Li, H. Wang, Y. Shimizu, A. Pyatenko, K. Kawaguchi and N. Koshizaki, Chem. Commun., 2011, 47, 932-934.

51 W. Sukkabot, Phys. Rev. B, 2017, 506, 192-197.

52 J. Pérez-Conde, A. K. Bhattacharjee, M. Chamarro, P. Lavallard, V. D. Petrikov and A. A. Lipovskii, Phys. Rev. B: Condens. Matter Mater. Phys., 2001, 64, 113303.

53 Y. Zhang, R. Yuan, M. He, G. Hu, J. Jiang, T. Xu, L. Zhou, W. Chen, W. Xiang and X. Liang, Nanoscale, 2017, 9, 17849-17858.

54 Y. Zhang, R. Yuan, M. He, G. Hu, J. Jiang, T. Xu, L. Zhou, W. Chen, W. Xiang and X. Liang, Nanoscale, 2017, 9, 17849-17858. 